\title{
Pregnant women's perception of cesarean section on demand
}

\author{
Sibil Tschudin ${ }^{1, *}$, Judith Alder ${ }^{1}$, Stephanie \\ Hendriksen', Johannes Bitzer', Karoline Aebi \\ Popp1, Rosanna Zanetti', Irene Hösli', \\ Wolfgang Holzgreve ${ }^{1}$ and Verena Geissbühler ${ }^{2}$ \\ ${ }^{1}$ Department of Obstetrics and Gynecology, University \\ of Basel, Switzerland \\ 2 Kantonsspital Frauenfeld, Switzerland
}

\begin{abstract}
Aims: To assess pregnant women's awareness of and attitudes towards cesarean section (CS) on demand, as well as to identify specific target groups by focusing on differences dependant on the participants' background, parity and intended mode of delivery.

Methods: The study was conducted at two centers during three months. German-speaking pregnant women were invited to answer an anonymous, structured questionnaire. We compared urban vs. rural, nulliparous vs. parous and women opting for a CS vs. denying this wish, with regard to awareness and attitudes towards CS on demand.

Results: Ninety-two percent of the 201 participants were aware of the possibility to deliver by CS on demand. Their sources of information were mostly print media reports, television, or friends. Pain avoidance and missing the birth experience were the main reasons for and against CS on demand, respectively. For women opting for CS on demand, traumatically-experienced previous birth and the child's well-being were other important reasons for a CS.

Conclusions: Because negative birth experience appears to be decisive for pregnant women's attitude towards CS on demand and their perception of CS seems to be partly based on misconceptions, antenatal counseling should focus on these aspects.
\end{abstract}

Keywords: Antenatal counseling; birth experience; cesarean section on demand; decision making; perception of cesarean section on demand; pregnant women.

\footnotetext{
${ }^{\star}$ Corresponding author:

Sibil Tschudin, MD

Division of Social Medicine and Psychosomatics

Department of Obstetrics and Gynecology

University of Basel

Spitalstrasse 21

$\mathrm{CH}-4031$ Basel

Switzerland

Tel.: +41613259067

Fax: +41613259035

E-mail: stschudin@uhbs.ch
}

\section{Introduction}

The rate of cesarean section (CS) has increased ten-fold during the last 50 years and comprised $29.3 \%$ of all deliveries in Switzerland in 2003 and 28\% in Germany in $2005[4,6]$. The rising percentage of CS performed without medical or obstetrical indications but rather on pregnant women's demand contributes to this overall increase in the rate of CS. The percentage of CS on demand varies between $2.6 \%$ of all CS in Flanders and $13 \%$ (public hospital) to 19\% (private hospital) in Brazil $[19,21]$. In 1998, FIGO published ethical considerations regarding deliveries by CS for non-medical reasons and recommended against CS on demand, as there is inadequate evidence-based information regarding the risks and benefits $[11,13,16,24,26]$. This statement seems to contrast not only with the perception of those pregnant women who favor a CS, but also with the results of several surveys of gynecologists in different countries. They revealed that up to $31 \%$ of gynecologists would choose an elective CS for themselves or their partners $[1,10,17,19]$. While gynecologists were mainly concerned about possible damages to the pelvic floor, and to a lower extent about impaired sexuality, pregnant women's reasons for a CS on demand were primarily comprised of concerns for the child's well-being and the fear of stress and pain during labor [2, 3, 7, 25]. According to the existing literature, these emotional aspects as well as additional psychological factors, such as anxiety and a negative previous birth experience, are decisive [8, $22,23]$. A review of 17 studies by McCourt et al. made evident that cultural, institutional and professional settings of decision-making may play an important role, as well $[9,18]$. In 2004, the National Institute for Health and Clinical Excellence (NICE) recommended that further research should be carried out to evaluate the reasons that lead to pregnant women's request for CS [20].

The objective of our study was to gain insight into pregnant women's awareness of CS on demand, their sources of information and their attitudes towards this mode of delivery. The study was conducted at a rural and an urban obstetrical center in Switzerland. The research questions focused on identifying possible differences in intentions and needs of specific target groups and addressed the following issues:

When comparing participants receiving prenatal care at the urban vs. the rural center, nulliparous women vs. those with at least one previous delivery, and women 
considering (CS-group) vs. not considering CS on demand (vaginal delivery/VD-group), are there

1. Differences of awareness with regard to CS on demand?

2. Differences of attitudes towards CS on demand? difference between the CS- and VD-group was evident. For research question 1, the two groups were evaluated with regard to awareness of CS on demand (knowledge of this mode of delivery), and for research question 2 with regard to their attitudes towards it (access to this mode of delivery and main reasons for and against it) using $\chi^{2}$-tests. A P $<0.05$ was considered significant.

\section{Results}

A total of 201 questionnaires were completed: 96 (47.8\%) from the urban and $105(52.2 \%)$ from the rural center. The collaborating obstetricians' contribution to recruitment of participants at the urban and rural sites was $49.0 \%$ and $28.6 \%$, respectively. The mean age of participants was 31.6 (SD 5.0) years, ranging from 20 to 44 years. Twenty-nine percent of the women graduated from a college or university, and $50 \%$ of them had completed a professional training. Sixty-seven percent were Swiss, $27 \%$ came originally from other European countries and a minority of $5.5 \%$ from other continents. Half of the women were nulliparous, and $12 \%$ had already given birth to more than one child. Further socio-demographic and obstetric characteristics are shown in Table 1. Comparing women attending the urban with those attending the rural site revealed no significant differences with regard to demographic data.

Out of the 201 participants, 195 women (97\%) answered the question whether they would preferably deliver by CS on demand: 19 (9.7\%) answered yes, 15 $(7.7 \%)$ were uncertain and $161(82.6 \%)$ answered no. Data of the six women not answering the question concerning the preferred mode of delivery were taken into account with regard to descriptive statistics and comparison between urban and rural group, as well as parity, but had to be excluded from comparison between the CS- and VD-group.

\section{Awareness and information}

One hundred and eighty-five women (92\%) stated that they had heard about CS on demand. Figure 1 shows how frequent the various sources of information were named. Seven women indicated their professional background, and four women a discussion with a midwife or information meetings under "other" sources of information.

When comparing the respective subgroups, women attending the urban center mentioned more often friends $(P=0.027)$ as source of information, parous women print media $(P=0.042)$ and television $(P=0.023)$ and women of the CS-group their obstetricians ( $P=0.001)$.

\section{Attitudes towards CS on demand}

Table 2 lists the reasons for and against CS, from which the participants had to choose the respective reason that ranked highest for them. The frequencies with which the making a distinction between the two subgroups (affirmative and considering, respectively) would have been arbitrary, while the 
Table 1 Socio-demographic and obstetric characteristics $(n=201)$.

\begin{tabular}{|c|c|}
\hline Mean age (SD) & $31.6(5.0)$ years \\
\hline Age range & $20-44$ years \\
\hline \multicolumn{2}{|l|}{ Nationality $(n=201)$} \\
\hline Switzerland & $134(66.7 \%)$ \\
\hline European country & $51(26.3 \%)$ \\
\hline Other continent & $11(5.5 \%)$ \\
\hline No answer & $5(2.5 \%)$ \\
\hline \multicolumn{2}{|c|}{ Educational level $(n=197)$} \\
\hline No formation & $2(1.0 \%)$ \\
\hline Secondary school & $20(10.2 \%)$ \\
\hline Vocational training & $13(6.6 \%)$ \\
\hline Professional training & $100(50.8 \%)$ \\
\hline College/university & $57(28.9 \%)$ \\
\hline No answer & $5(2.5 \%)$ \\
\hline \multicolumn{2}{|l|}{ Parity $(n=199)$} \\
\hline 0-para & $102(51.3 \%)$ \\
\hline I-para & $73(36.7 \%)$ \\
\hline II-para & $18(9.0 \%)$ \\
\hline III-para & $5(2.5 \%)$ \\
\hline IV-para & $1(0.5 \%)$ \\
\hline \multicolumn{2}{|c|}{ Mode of delivery first delivery $(n=96)$} \\
\hline Spontaneous & $55(57.3 \%)$ \\
\hline Vacuum/Forceps & $16(16.6 \%)$ \\
\hline Emergency CS & $11(11.5 \%)$ \\
\hline Elective CS & $13(13.6 \%)$ \\
\hline CS on demand & $1(1 \%)$ \\
\hline \multicolumn{2}{|c|}{$2^{\text {nd }}$ and $3^{\text {rd }}$ delivery $(n=30)$} \\
\hline Spontaneous & $24(80.0 \%)$ \\
\hline Vacuum/Forceps & $2(6.7 \%)$ \\
\hline Emergency CS & $1(3.3 \%)$ \\
\hline Elective CS & $3(10.0 \%)$ \\
\hline CS on demand & - \\
\hline
\end{tabular}

items were chosen by all participants and by those of the VD-group and CS-group are presented, as well as the women's estimation with regard to the offer of and the access to CS on demand. As there were no differences when comparing the urban- and rural-group as well as the nulliparous and parous women, these data are not presented separately. "No pain during labor" was the most frequently chosen reason for CS on demand. Comparison between the VD- and CS-group revealed, however, that for women considering CS, pain avoidance during labor was less predominant as the main reason (67.1\% and $43.8 \%$, respectively, $\mathrm{P}=0.016)$. Instead, three of them mentioned a traumatic experience in a previous birth and six of them fears of peripartal complications under "other reasons". Missing the birth experience was most frequently chosen as the reason against CS on demand. Again, this main reason was less often cited by women of the CS-group. They chose more often "surgical intervention with abdominal scar", and stated significantly more frequently that there exists "no reason against a CS on demand" at all $(P=0.0001)$.

Concerning their attitude towards CS on demand in general, $40 \%$ of the participants were in favor of the possibility of and the access to a CS on demand for every pregnant woman, while almost the same percentage (38.5\%) argued against it. Women of the CS-group were significantly more often in favor of this option and less often against it than women of the VD-group $(P=0.002$ and 0.004 , respectively).

\section{Discussion}

The main findings of our survey on pregnant women's perception of CS on demand were that almost all women were aware of this mode of delivery, $10 \%$ seriously considered delivering by CS on demand, and $40 \%$ declared that CS on demand should be available for all pregnant

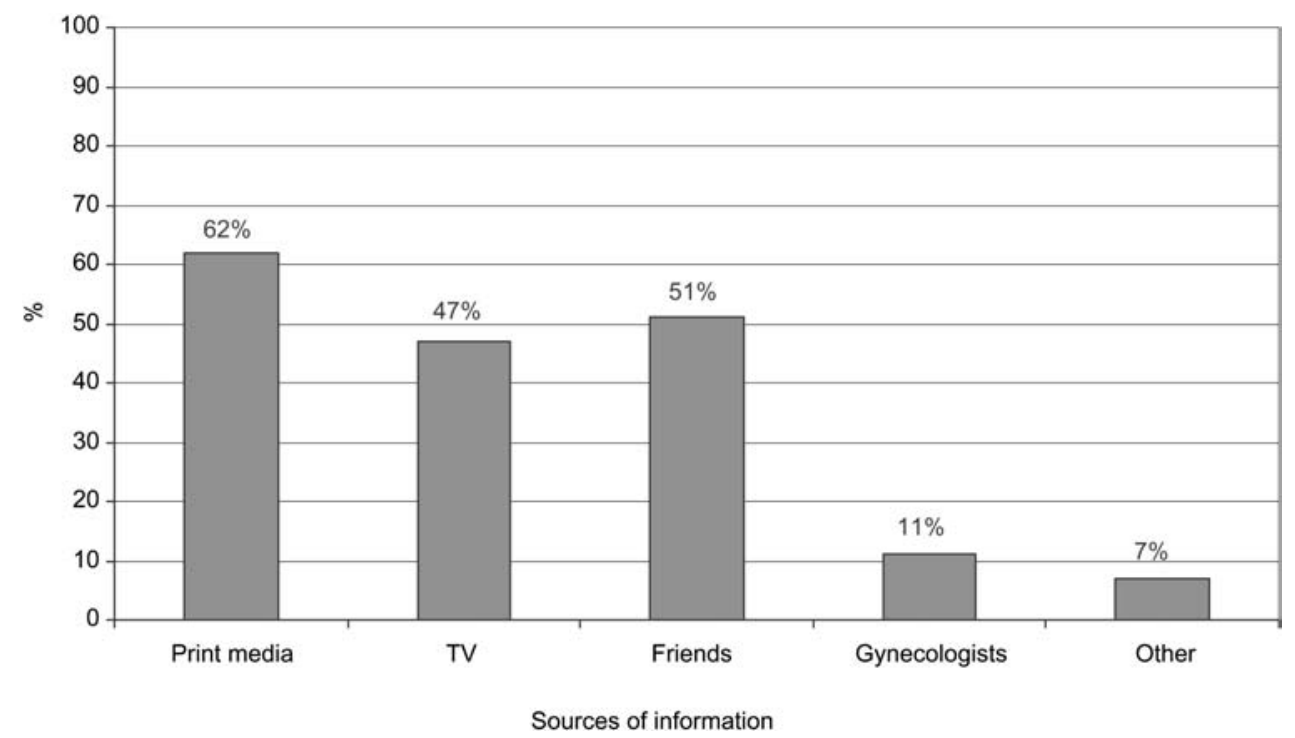

Figure 1 Sources of information about CS on demand.

(Frequency of citation in percent, several answers were allowed). 
Table 2 Cesarean section on demand: Women's attitude, main reason for and against CS on demand for all women, those considering vaginal delivery (VD-group) and those opting for CS on demand (CS-group).

\begin{tabular}{|c|c|c|c|c|c|c|c|}
\hline & \multicolumn{2}{|l|}{ Total } & \multicolumn{2}{|c|}{ VD-group } & \multicolumn{2}{|c|}{ CS-group } & \multirow{2}{*}{$\begin{array}{l}\text { Significance } \\
\text { P }\end{array}$} \\
\hline & $\mathrm{n}$ & (\%) & $\mathrm{n}$ & (\%) & $\mathrm{n}$ & (\%) & \\
\hline Main reason for CS & $184^{\star}$ & $(100.0)$ & $146^{\star}$ & $(100.0)$ & $32^{*}$ & $(100.0)$ & \\
\hline No pain during labor & 114 & $(62.0)$ & 98 & $(67.1)$ & 14 & $(43.8)$ & $0.016^{\star *}$ \\
\hline No perineal damage & 17 & $(9.2)$ & 12 & $(8.2)$ & 3 & $(9.4)$ & 0.735 \\
\hline No loss of control & 9 & $(4.9)$ & 6 & $(4.1)$ & 2 & (6.3) & 0.063 \\
\hline Less risky for the child & 6 & (3.3) & 4 & $(2.7)$ & 1 & (3.1) & 1.000 \\
\hline Time scheduling & 7 & (3.8) & 6 & $(4.1)$ & 1 & (3.1) & 1.000 \\
\hline Other & 15 & (8.2) & 6 & $(4.1)$ & 9 & $(28.1)$ & $0.0001^{\star *}$ \\
\hline No reason pro & 12 & $(6.5)$ & 11 & (7.5) & 1 & (3.1) & 0.696 \\
\hline Don't know & 4 & $(2.2)$ & 3 & $(2.1)$ & 1 & (3.1) & 0.551 \\
\hline Main reason against CS & $189^{*}$ & $(100.0)$ & $152^{*}$ & $(100.0)$ & $32^{*}$ & $(100.0)$ & \\
\hline No birth experience & 101 & $(53.4)$ & 87 & $(57.2)$ & 12 & $(37.5)$ & 0.051 \\
\hline More pain $\mathrm{pp}$ & 11 & $(5.8)$ & 8 & $(5.3)$ & 2 & (6.3) & 0.686 \\
\hline Surgery with abdominal scar & 23 & (12.2) & 16 & $(10.5)$ & 7 & (21.9) & 0.085 \\
\hline Riskier for mother & 21 & (11.1) & 19 & (12.5) & 1 & (3.1) & 0.207 \\
\hline Riskier for child & 6 & $(3.2)$ & 3 & $(2.0)$ & 2 & (6.3) & 0.209 \\
\hline Other & 16 & $(8.5)$ & 15 & $(9.9)$ & 1 & (3.1) & 0.313 \\
\hline No reason contra & 8 & $(4.2)$ & 2 & $(1.3)$ & 6 & $(18.8)$ & $0.0001^{\star \star}$ \\
\hline Don’t know & 3 & (1.6) & 2 & (1.3) & 1 & $(3.1)$ & 0.438 \\
\hline Attitude towards CS on demand & $195^{\star}$ & $(100.0)$ & $155^{\star}$ & $(100.0)$ & $34^{\star}$ & $(100.0)$ & \\
\hline Pro & 78 & $(40.0)$ & 52 & (33.5) & 22 & $(64.7)$ & $0.002^{\star \star}$ \\
\hline Contra & 75 & (38.5) & 69 & $(44.5)$ & 6 & $(17.6)$ & $0.004^{\star *}$ \\
\hline Uncertain & 42 & $(21.5)$ & 34 & (21.9) & 6 & (17.6) & 0.651 \\
\hline
\end{tabular}

${ }^{*}$ Number referring to the total of respondents for each question. Differences between the sum of the two groups and total are due to missing values.

${ }^{\star *}$ Denotes those variables significant at $\mathrm{P}<0.05$ level.

women. With regard to awareness and attitudes, there were generally no differences between women from the urban and rural center as well as between nulliparous and parous women, but existed between those of the VD- and the CS-group.

\section{Awareness and information}

More than $90 \%$ of the participants were aware of the possibility to deliver by means of a CS on demand. Their sources of information were print media reports, television or friends. Women opting for a CS received their information more often from obstetricians. This pattern seems to reflect the fact that CS on demand is an issue currently discussed in the media. Based on the findings in our sample, there is no evidence that the issue is very frequently broached by gynecologists, but might rather be addressed by pregnant women opting for this mode of delivery.

\section{Attitudes towards CS on demand}

Ten percent of the participants stated that they would hypothetically deliver by CS on demand without medical or obstetrical indications, while another $7.5 \%$ seemed to at least consider this opportunity, but were still uncertain.
This corresponds to surveys from UK and USA where $13-20 \%$ of pregnant women would prefer a CS $[14,15]$ and contradicts the review of McCourt that only a minority of women request a CS [18]. Gamble et al. demonstrated by means of a meta-analysis that in ten selected studies, the overwhelming majority of women requesting CS on demand had a previous complicated birth [7]. Even if a delivery without medical complications may be experienced as traumatic, vaginal operative deliveries and emergency CS are typically experienced as more negative. A negative birth experience seems to play a crucial role with regard to the request for a CS [5, 27]. We found that, besides the avoidance of pain during labor for several women (especially those opting for CS on demand), a negative birth experience and concerns of the child's well-being were important or the main reasons for a CS on demand. This pattern reveals that women with previously negative birth experiences seem to be led by their experience and concerns, while the answers of the others is more based on assumptions. The predominance of the mentioned factors is in accordance with the results of previous studies [2, 3, 25]. Women opting for CS on demand seem to assume that CS is less harmful to the child, and not to consider epidural anesthesia for pain relief during labor. As proposed by Simpson et al., these misconceptions, as well as pre- 
existing and pregnancy related anxiety should be taken more into account in antenatal counseling [26].

Based on the results of their review, McCourt et al. questioned the high proportion of CS on demand presented by some authors and expressed their concerns with regard to conclusions on women's intentions to deliver by this mode [18]. In several studies, it remained unclear either how reasons for CS were determined or how women were counseled prior to decision-making. The authors concluded that contextual aspects, as well as socio-economical factors, may play a crucial role. In our study, intentions and attitudes did not differ between women attending the urban or rural center, and media and friends seemed to play a more important role in opinion-making than health professionals. The concern with regard to the child's well-being might reflect the demand for high standard and low risk medical care. When considering that almost as many women as those opting for CS on demand were ambivalent with regard to the preferred mode of delivery, and that negative birth experience was decisive for the intention to deliver by CS, early counseling adapted to individual needs and concerns is in our opinion crucial.

\section{Limitations}

The socio-demographic data showed that the participants' educational level was above average and that they were presumably highly motivated and therefore, represented a selected group, rather than being a national representation. As living in an urban or rural area has little impact on lifestyle in Switzerland nowadays, it is not surprising that there were no significant differences between the participants attending the urban and those attending the rural center. We therefore, declined from presenting detailed results focusing on this aspect. The questionnaire was administered anonymously, therefore not allowing any follow-up or obtaining of further information as to whether women considering CS on demand really received one and vice versa. Follow-up, on one hand, was not the aim of this survey, but is an objective of a still ongoing interventional trial at our study sites. On the other hand, the anonymity might have encouraged the participants to more freely express their opinion.

\section{Conclusions}

Our findings suggest that for about $10 \%$ of pregnant women in Switzerland, CS on demand is of major interest and concern. The majority of pregnant women seem to be aware of this option, and in our survey, almost half of them were in favor of free access to this mode of delivery for all women. As negative birth experience appears to be decisive for pregnant women's attitude towards CS on demand and their perception of CS seems to be partly based on misconceptions, antenatal counseling should be attentive to and take into consideration all these aspects and they should be addressed early in pregnancy.

\section{References}

[1] Al-Mufti R, McCarthy A, Fisk N. Survey of obstetricians' personal preference and discretionary practice. Eur J Obstet Gynecol Reprod Biol. 1997;73:1-4.

[2] Béhague D, Victoria C, Barros F. Consumer demand for caesarean sections in Brazil: informed decision-making, patient choice, or social inequality? A population based birth cohort study linking ethnographic and epidemiological methods. Br Med J. 2002;324:1-6.

[3] Chong E, Mongelli M. Attitudes of Singapore women toward caesarean and vaginal deliveries. Int J Gynaecol Obstet. 2003;80:189-94.

[4] Codelnfo 2/05, №18, Swiss Federal Statistical Office.

[5] Creedy DK, Shochet IM, Horsfall J. Childbirth and the development of acute trauma symptoms: incidence and contributing factors. Birth. 2000;27:104-11.

[6] Federal Statistical Office, Wiesbaden. Pressemitteilung Nr. 050 vom 07.02.2007.

[7] Gamble JA, Health M, Creedy DK. Women's request for a caesarean section: a critique of the literature. Birth. 2000; 27:256-63.

[8] Gamble JA, Creedy DK. Women's preference for a cesarean section: incidence and associated factors. Birth. 2001;28:101-10.

[9] Gamble JA, Creedy DK, McCourt C, Weaver J, Beake S. A critique of the literature on women's request for cesarean section. Birth. 2007;34:331-40.

[10] Gonen R, Tamir A, Degani S. Obstetricians' opinions regarding patient choice in cesarean delivery. Obstet Gynecol. 2002;99:577-80.

[11] Hansen AK, Wisborg K, Uldbjerg N, Henriksen TB. Risk of respiratory morbidity in term infants delivered by elective caesarean section: cohort study. Br Med J. 2008;336: 85-7.

[12] Huizink AC, Mulder EJH, Robles de Medina PG, Visser GHA, Buitelaar JK. Is pregnancy anxiety a distinctive syndrome? Early Hum Dev. 2004;79:81-91.

[13] Jacquemyn Y, Ahankour F, Martens G. Flemish obstetricians' personal preference regarding mode of delivery and attitude towards caesarean section on demand. Eur $\mathrm{J}$ Obstet Gynecol Reprod Biol. 2003;111:164-6.

[14] Johanson RB, El-Timini S, Rigby C, Young P, Jones P. Caesarean section by choice could fulfil the inverse care law. Eur J Obstet Gynecol Reprod Biol. 2001;97:20-2.

[15] Lapeyre E, Finan M, Hedges S, Lovitt S, Magnus M. Patient choice for elective cesarean delivery: report on a survey. The Female Patient. 2004;29:12-21.

[16] Ludwig H, Loeffler FE. Caesarean section on demand - an ethical dilemma. Arch Gynecol Obstet. 2001:264:169-70.

[17] MacDonald C, Pinion SB, MacLeod UM. Scottish female obstetricians' view on elective caesarean section and personal choice for delivery. J Obstet Gynaecol. 2002;22: 586-9.

[18] McCourt C, Weaver J, Statham H, Beake S, Gamble J, Creedy DK. Elective cesarean section and decision making: a critical review of the literature. Birth. 2007;34:65-79. 
[19] Miesnik SR, Reale BJ. A review of issues surrounding medically elective cesarean delivery. J Obstet Gynecol Neonatal Nurs. 2007;36:605-15.

[20] NICE guidelines: Caesarean section. London, 2004.

[21] Potter J, Berquó E, Perpétuo H, Leal O, Hopkins K, Souza $\mathrm{M}$, et al. Unwanted caesarean sections among public and private patients in Brazil: prospective study. $\mathrm{Br}$ Med $\mathrm{J}$. 2001;323:1155-8.

[22] Ryding EL. Psychosocial indications for cesarean section A retrospective study of 43 cases. Acta Obstet Gyneco Scand. 1991;70:47-9.

[23] Ryding EL. Investigation of 33 women who demanded a cesarean section for personal reasons. Acta Obstet Gynecol Scand. 1993;72:280-5.

[24] Schenker JG, Cain JM. FIGO Committee Report. FIGO Committee for the Ethical Aspects of Human Reproduction and Women's Health. International Federation of Gynecology and Obstetrics, Int J Gynaecol Obstet. 1999;64 317-22.
[25] Schindl M, Birner P, Reingrabner M, Joura E. Husslein P, Langer M. Elective caesarean section vs. spontaneous delivery: a comparative study of birth experience. Acta Obstet Gynecol Scand. 2003;82:834-40.

[26] Simpson KR, Thorman KE. Obstetric "conveniences": elective induction of labour, caesarean birth on demand, and other potentially unnecessary intervention. J Perinat Neonatal Nurs. 2005;19:134-44.

[27] Söderquist J, Wijma K, Wijma B. Traumatic stress after childbirth: the role of obstetric variables. J Psychosom Obstet Gynaecol. 2002;23:31-9.

The authors stated that there are no conflicts of interest regarding the publication of this article.

Received July 18, 2008. Revised September 30, 2008. Accepted October 7, 2008. Previously published online February 6, 2009. 